\title{
CONSTRUCTION PRACTICES FOR FIRST EVER WHEAT STRAW REINFORCED CONCRETE PAVEMENT FOR LIGHT TRAFFIC
}

\author{
Muhammad Usman Farooqi ${ }^{1}$ and Majid $\mathrm{Ali}^{2}$ \\ ${ }^{1,2}$ Civil Engineering Department, Capital University of Science and Technology, \\ Islamabad, Pakistan \\ 1)m.usman@ cust.edu.pk ${ }^{2)}$ drmajidali15@gmail.com
}

\begin{abstract}
Pavements are the backbone of any country's economy. Construction industry in developing countries like Pakistan are shifting the pavements from flexible to rigid ones to accommodate the heavy traffic and weak foundations. However, the higher initial cost of rigid pavements is still the point of concern. Researches have been made to economize the cost of concrete pavements along with improving it's behavior. The overall motive of this research program is to have sustainable and economical pavements for the prosperity of country. In this study, the construction practice for the laying of first ever wheat straw reinforced concrete (WSRC) pavement has been discussed. Plain concrete (PC) panels are also cast for reference. Test sections are made in university campus for light traffic. A total of 30 meters pavement having width of 5.5 meters is constructed. The total length is divided in five panels of size $6 \times 5.5$ meters; three with PC and two with WSRC. Concrete workability, laying process, compaction efforts, and finishing issues are reported. The early-age micro shrinkage at 3-days and 7-days is evaluated. Discussions on the findings are made. Although, some hindrances are there in laying of WSRC pavement due to unskilled labour and non-conventional material. But overall, WSRC road sections show better early-age behavior in terms of shrinkage as compared to that of PC road sections.
\end{abstract}

Keywords: Rigid pavement, natural fibres, wheat straw, micro-shrinkage cracking, wheat straw reinforced concrete.

\section{INTRODUCTION}

Pavements are broadly classified into flexible and rigid ones. Contrary to bituminous pavements, cement concrete pavements can provide better and sustainable solution to 
heavy traffic loading and weak foundations due to long-term durability because of concrete's high strength and low maintenance cost (Bordelon et al., 2015). However, the initial cost of concrete pavement is very high due to which it's still not used widely. The higher cost of rigid pavements is due to the higher expenses of steel. Steel reinforcement is embedded in concrete to reduce the brittleness of concrete which ultimately reduces the rigid pavement distresses. As rigid pavements are usually prone to early age distresses due to low tensile strength and strain capacity. Some of the distresses are shown in Figure 1.
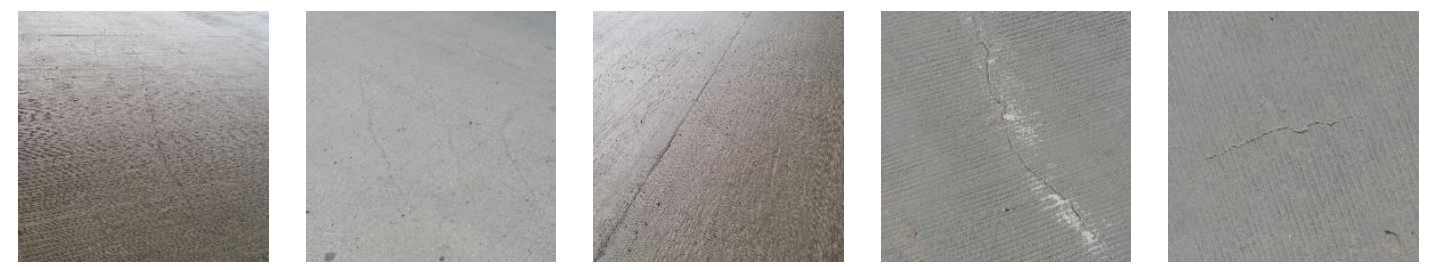

Figure 1. Early age cracks in newly constructed rigid pavements

D'Ambrosia et al. highlighted the issue of early age micro cracking as the primary issue in rigid pavements. Shrinkage reducing admixtures were used to reduce shrinkage and creep in concrete pavements. Uni-axial test under restrained conditions and constant compressive/tensile loading was performed on the sampled specimen. A decrease (up to $30 \%$ ) in the early-age micro-shrinkage cracking of concrete was observed with an admixture dosage of $0.75 \mathrm{gal} / \mathrm{yd}^{3}$. However, the distresses mostly occurred in concrete pavements of developing countries were also reported by many researchers. Some are given in Table 1.

Table 1: Commonly occurred distresses in rigid pavements of developing countries

\begin{tabular}{cl}
\hline \multicolumn{1}{c}{ Distresses } & \multicolumn{1}{c}{ References } \\
\hline i. Durability Cracking & \multicolumn{1}{c}{ Gupta et al. 2011; Suja et } \\
ii. Micro-shrinkage cracking & $\begin{array}{l}\text { al. 2016; Kanalli et al. } \\
\text { 2014; Kumar et al. 2015; }\end{array}$ \\
iii. Longitudinal cracking & Subramani et al. 2016 \\
iv. Transverse cracking & \\
v. Punchouts & \\
\hline
\end{tabular}

Efforts have been made in recent studies to use the dispersed fibres in concrete for enhancing the ductility/toughness of concrete. The addition of dispersed artificial/steel fibres in cement concrete composites, for pavement applications, has also been studied in many researches (Ramakrishnan et al., 1989; Achilleos et al., 2011; Gupta et al., 2011; Graef et al., 2012; Salemi and Behfarnia, 2013; Rai and Joshi, 2014; Sinha et al., 
2014; Kanalli et al., 2014; Paramod et al., 2015; Kumar et al., 2015). Generally improved behavior of fibre reinforced concrete, for rigid pavement applications, is observed compared to that of plain concrete. The incorporation of steel fibres in concrete pavement improves the mechanical properties of concrete, resulting in significant increase in it's load carrying capacity even after cracking (Chen, S. 2004). The incorporation of dispersed fibres basically resists the first crack formation due to sewing effect. Furthermore, the process of propagation of cracks is also elongated due to the cracks arresting of uniformly distributed fibres. Thus, resulting in enhancement of composite's load carrying capacity. The addition of fibres in concrete can also lead towards high tensile strength and strain capacity allowing reduction of pavement layer thickness (Mohammadi et al. 2009). Sinha et al. (2014) also reported that the use of fibres can lead to reduction in pavement depth by reducing the reinforcement and thus reducing the overall costs.

As far as use of natural fibres for concrete pavement applications is concerned; as discussed earlier, natural fibre reinforced concrete is comparable with artificial fibre reinforced concrete and steel fibre reinforced concrete. Hence, the limited studies have also been made on natural fibre reinforced concrete for rigid pavement applications. But, to the best of author's knowledge, these studies are done with limited scope yet. Sugarcane bagasse fibre reinforced concrete was investigated by Patel D and Patel V (2015) for pavement applications. Three fibre contents i.e. $0.5 \%, 1 \%$, and $1.5 \%$ (by weight of concrete) were used with the aspect ratios of $30,60 \& 90$. The optimum content and aspect ratio came out to be $1 \%$ and 90 , respectively. An increase of $6 \%$ in flexural strength and 9\% in compressive strength of concrete was observed at this optimized material. Khan and Ali (2018) has also studied hair fibre reinforced concrete for concrete pavements. The compressive, splitting-tensile, and flexural strengths of concrete reinforced with hair fibres were increased by $12.4 \%, 16.2 \%$, and $19.1 \%$, respectively. The study also reported that the pavement thickness of hair fibre reinforced concrete was reduced by 0.5 inches when compared to that of reference concrete for particular loading conditions. During the construction of rigid pavements, many issues can be expected since this procedure is refined, and includes numerous exercises like concrete placing, spreading, compacting, finishing, texturing, curing, protecting, jointing, testing, and other sub-activities Professionals who have expertise in construction-engineering services concluded that there are constantly adverse outcomes during construction process, which cannot predictable during design experimentation in the laboratories under ideal conditions (ACI 224.1R-07, 2007).

The construction of rigid pavements in developing countries like Pakistan is increasing in the recent decade to facilitate heavy traffic vehicles used for freight transportation. But the higher initial cost and early age distresses is the reason for exploring new economical and durable materials. In a recent study made by Farooqi and Ali (2018), the wheat straw reinforced concrete is presented as a potential construction material for civil engineering applications especially rigid pavements. But the preparation of wheat 
straw reinforced concrete in a bulk quantity and the construction practices for laying of wheat straw reinforced concrete on a large scale is still a question. In this study, these pavements are prone to a number of distresses. Distresses like polished aggregates, scaling, transverse cracks, corner breaks, and erosion of sub-base in concrete pavements was found by Suja et al. (2016) in Srilanka. As Pakistan and Srilanka both are Asian countries with same climatic conditions and nearest similar transportation infrastructure. Hence, environmental and traffic loading upon pavements can be relate able. The overall purpose of this project is to propose sustainable design/construction. As per author's best knowledge, no such study has been conducted yet. In this study, the construction practice for the laying of first ever wheat straw reinforced concrete (WSRC) pavement has been discussed in detail. Plain concrete (PC) panels are also cast for reference. Test sections are made in university campus for light traffic.

\section{PROCEDURE}

\section{Materials:}

The basic constituents used in preparation of PC and WSRC test sections are Ordinary Portland Cement (OPC), locally available sand, aggregates, potable/tap water and commercially available wheat straw. The production of OPC from a local brand (i.e. Bestway) is as per EN 197_1: 2011-CEM I 42_5N i.e. having 52 3 MPa strength at 28 days. The maximum size of aggregates used is $19.5 \mathrm{~mm}$. Agricultural residues of wheat crop (i.e. wheat straw), which are commercially available in a near-by source, are used. The length of wheat straw, which was available commercially, is $25 \mathrm{~mm}$. Commercially (local) available wheat straw is taken by a random selection. The approximate linear dimensions of wheat straw (randomly obtained) are $25 \mathrm{~mm} \times 5 \mathrm{~mm} \times 1.2 \mathrm{~mm}$. These straw are dipped in potable water for 15 to 20 minutes. This dipping is purposed to remove the wax/impurities/dust from the straw surface. After that, straw are removed from the water and then air-dried.

\section{Mixing:}

The proportions for mix of plain concrete are 1:4:8 (cement: sand: aggregate) having w/c ratio of 0.60 . For the preparation of PC mix: cement, sand and aggregates are simultaneously put in the drum mixer and water is then added. The mixer is started to rotate for a period of five minutes. Slump test was performed before placement of concrete and the value of slump was 1-inch (Figure 2a). Whereas, for making WSRC, wheat straw having approximate length of $25 \mathrm{~mm}$ and content of $1 \%$, by mass of wet concrete, are added with $0.60 \mathrm{w} / \mathrm{c}$ ratio. For preparation of WSRC: $1 / 3 \mathrm{rd}$ of cement, sand, aggregates and straw are put in the drum mixer in four layers. The remaining cement, sand, aggregates, and straw are then added in the drum mixer using the same layering technique. $2 / 3 \mathrm{rd}$ of water is then added and mixer is rotated for three-minutes. The $1 / 3$ rd water is then added and the drum mixer is started again to rotate for two minutes to get the homogenous and workable WSRC mix. Slump test for WRSC was also performed in the same manner as performed for PC. Zero-slump was observed in 
case of WSRC (Figure 2b). The reason for less slump value for WSRC may be due to water absorption by straw.

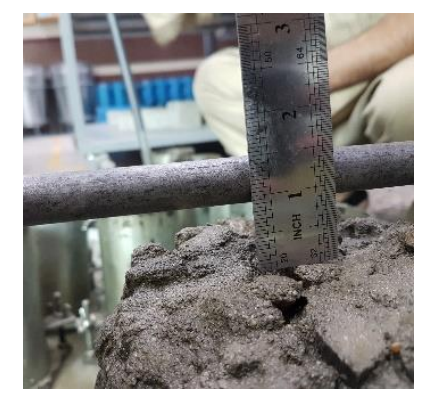

(a)

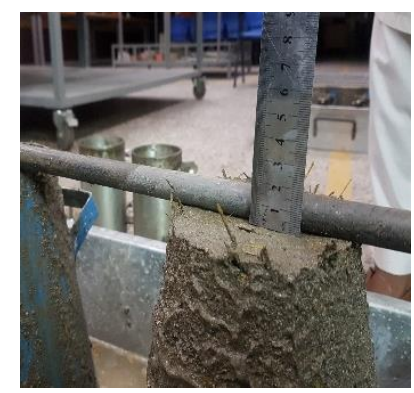

(b)

Figure 2. Slump test (a) PC and (b) WSRC

\section{Laying:}

Concrete pavement test sections are constructed in university campus for light traffic. A total of 30 meters section having width of 5.5 meters is constructed. The total length is divided in five panels of size $6 \times 5.5$ sq. meters each; three with PC and two with WSRC. Soil surface/layer was prepared with the help of excavator (Figure 3a). A 50 $\mathrm{mm}$ layer of plain concrete was laid to have a smooth base for pouring PC and WSRC. The depth for both PC and WSRC layers is $150 \mathrm{~mm}$ which was maintained with the help of concrete spacers (Figure 3b). PC and WSRC was transported from mixer/batcher to the site with the help of wheel barrows (Figure 3c). PC and WSRC were poured and laid then manually and levelled by using strike off board and Darby (Figure 3d). In case of WSRC, extra effort was made in spreading and finishing. Finishing trowel was used to get the smooth surface as straw were appeared on the surface. At some locations the length of chipped off straw was up to its half-length which were then removed manually from the surface during finishing process. A smooth surface of WSRC is achieved by putting extra efforts in comparison to that of PC (Figure 3e). 


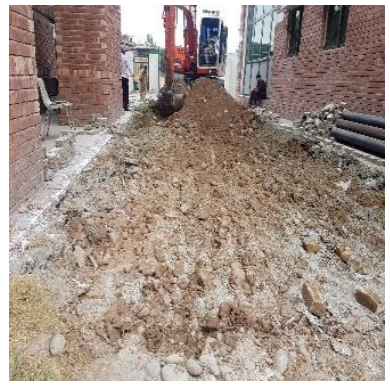

(a)

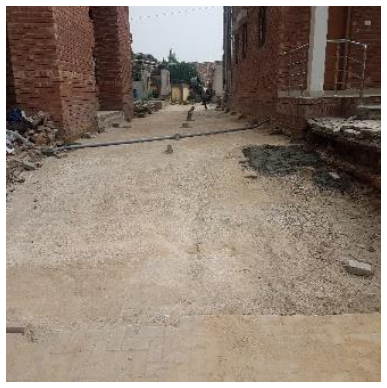

(b)

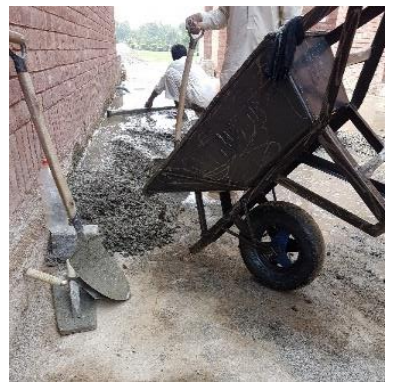

(c)

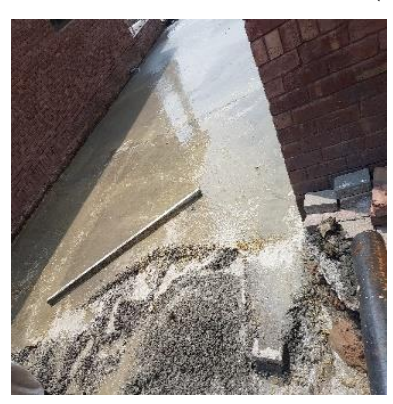

(d)

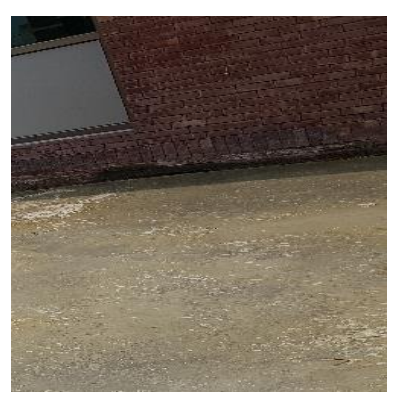

(e)

Figure 3. Laying Process (a) Soil layer preperation (b) Surface preperation with levels (c) Laying of concrete (d) Levelling (e) Finish surface

\section{OBSERVATIONS}

\section{Crack Formation:}

Figure 4 shows the grid arrangement which was adopted to observe the shrinkage cracking in test sections. The total dimensions of studied two test sections were $12 \times 11$ sq. meters, each having a length of $6 \mathrm{~m}$ and width of $5.5 \mathrm{~m}$. Grids of 1 x 0.9 sq. meters were adopted to further divide these two panels into small rectangles, so that observation of shrinkage cracking could be made easily. This grid system in practical on panels was made by using plaster of paris. Shrinkage cracking at 3-days after construction and at 7-days was being observed and recorded. In this way, crack development and its propagation were recorded. It was observed that only one crack was appeared on WSRC test section up to 7 days age (Figure 4b). 
(a)

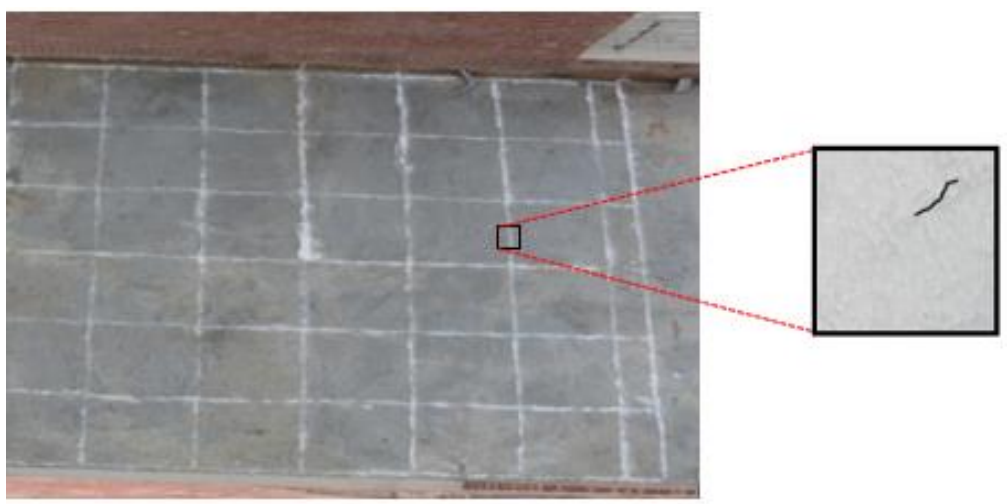

(b)

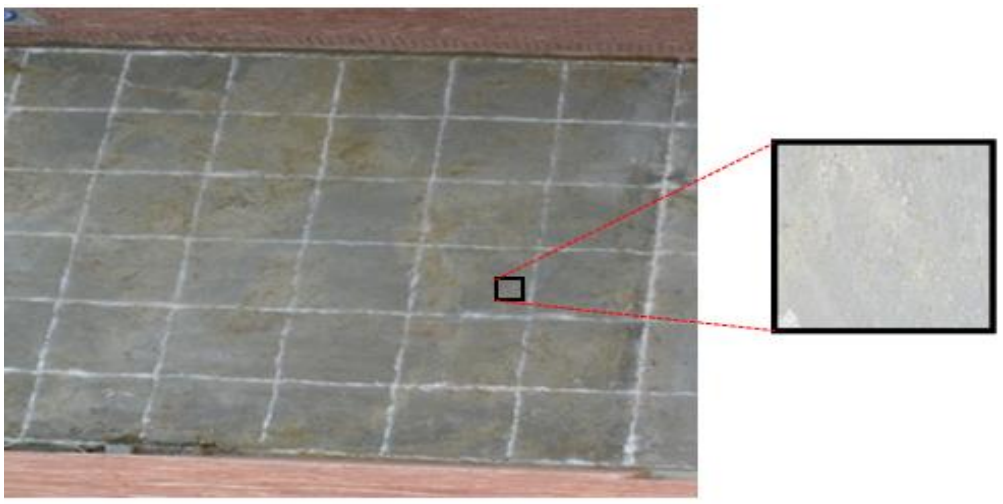

Figure 4. Formation of cracks in (a) PC and (b) WSRC test sections

Table 2 also illustrates the recorded data. The quantity of longitudinal and transverse cracks is counted and recorded at 3-days and 7-days age. The maximum length and width of cracks were also observed and recorded. Analysis of recorded data shows that shrinkage cracks elongate and expand by passing days in PC test section. However, in case of WSRC test section, the crack occurred after 3-days of construction. The quantity of developed cracks in WSRC is very less as compared to that in PC. And the crack propagation in case of WSRC is also very minute when compared to that in PC. The maximum observed length of crack in PC is $5.5 \mathrm{~mm}$ and $3.2 \mathrm{~mm}$ in WSRC. This behavior is due to interlocking/bridging/sewing effect because of the addition of dispersed straw in cement concrete composite.

Table 2: Development and propagation cracks in PC and WSRC test sections

\begin{tabular}{cccccccc}
\hline \multirow{2}{*}{ Observations } & \multicolumn{2}{c}{ No. of cracks } & \multicolumn{2}{c}{$\begin{array}{c}\text { Max length } \\
(\mathbf{m m})\end{array}$} & \multicolumn{2}{c}{$\begin{array}{c}\text { Max width } \\
(\mathbf{m m})\end{array}$} \\
\cline { 2 - 8 } & PC & WSRC & PC & WSRC & PC & WSRC \\
\hline 3-days & 02 & 00 & 2.9 & - & 0.35 & - \\
7-days & 05 & 01 & 5.5 & 3.2 & 0.58 & 0.35 \\
\hline
\end{tabular}




\section{Shrinkage:}

Linear Shrinkage is taken as percentage increase or decrease in the length of the specimen (ASTM C531-00; OPSS LS-435 standard). Linear shrinkage i.e. percentage reduction in length of PC and WSRC test sections is given in Table 3. The reduction of $1.8 \%$ and $1 \%$ is observed in longitudinal length of PC and WSRC test sections, respectively. However, the reduction of $1.6 \%$ and $0.9 \%$ is observed in transverse dimensions of PC and WSRC, respectively. The reduction in linear shrinkage of WSRC test sections may be due to the dispersed straw and their uniform distribution in concrete.

Table 3: Linear shrinkage in PC and WSRC test sections

\begin{tabular}{ccc}
\hline \multirow{2}{*}{ Linear Shrinkage } & \multicolumn{2}{c}{$\%$ decrease } \\
\cline { 2 - 3 } & PC & WSRC \\
\hline Longitudinal & 1.8 & 1.0 \\
Transverse & 1.6 & 0.9 \\
\hline
\end{tabular}

\section{CONCLUSION}

Construction practices for construction of rigid pavement test sections including bulk quantity mixing, transporting, laying, compaction and finishing processes of Wheat Straw Reinforced Concrete (WSRC) are studied. Plain Concrete (PC) test sections are also constructed for reference. The conducted study is resulted in following findings:

- The slump of WSRC is decreased as compared to that of PC due to the water absorption capacity of dispersed straw in concrete.

- Following modifications in construction practices of WSRC are required, in addition to that for PC mix, to get homogenous and workable WSRC for rigid pavement application:

- Layered technique should be adopted in mixing of WSRC for uniform distribution of straw in concrete composite.

- Additional efforts are required for laying of WSRC to avoid the air voids which will be helpful in achieving high density. 
- Some extra measurements like vibratory compactors should be used for proper compaction of WSRC.

- Some dressing treatments are also required to at the surface of WSRC to get the proper finish of pavement and to avoid the voids on surface top due to the removal of straw.

- Early age micro-shrinkage cracking is observed in both PC and WSRC test sections. However, the quantity and severity of cracks in WSRC test section at 3-days and 7-days curing period are almost nothing as compared to that in PC test sections.

- A decrease of 55\% and 57\% is observed in the longitudinal and transverse linear shrinkage, respectively, of WSRC in comparison to that of PC.

So, it is concluded that the constructed WSRC pavement is likely to perform well for light traffic. The performance of pavement should be monitored and core testing should be performed to check fiber distribution and strength gain.

\section{ACKNOWLEDGEMENT}

The authors highly acknowledge the Capital University of Science and Technology, Islamabad, Pakistan for the research funding.

\section{REFERENCES}

ACI Committee 224. Causes, evaluation, and repair of cracks in concrete structures, ACI 224.1R-07. American Concrete Institute, 2007.

Achilleos, C., Hadjimitsis, D., Neocleous, K., Pilakoutas, K., Neophytou, P. O., \& Kallis, S. (2011). Proportioning of steel fibre reinforced concrete mixes for pavement construction and their impact on environment and cost. Sustainability, 3(7), 965-983.

Bordelon, A. C., Hiller, J. E., Roesler, J. R., \& Cervantes, V. G. (2015). Investigation of ESALs versus Load Spectra for Rigid Pavement Design. In Airfield and Highway Pavements 2015 (pp. 488-499).

Chen, S. (2004). Strength of steel fibre reinforced concrete ground slabs. Proceedings of the Institute of Civil Engineers, Structures, and Buildings (157), Issue SB2, 157-163

Graeff, A. G., Pilakoutas, K., Neocleous, K., \& Peres, M. V. N. (2012). Fatigue resistance and cracking mechanism of concrete pavements reinforced with recycled steel fibres recovered from post-consumer tyres. Engineering Structures, 45, 385-395.

Gupta, S., Rao, V. K., \& Sengupta, J. (2011). Evaluation of polyester fiber reinforced concrete for use in cement concrete pavement works. Road Materials and Pavement Design, 9(3), 441-461. 
Kanalli, S. A., Palankar, R., Kumar, B., Kumar, P., \& SK, P. (2014). Comparative study of polymer fibre reinforced concrete with conventional concrete pavement. IJRET: International Journal of Research in Engineering and Technology-ISSN, 2319-1163.

Khan, M. \& Ali, M. (2018). Effectiveness of hair and wave polypropylene fibres for concrete roads. Construction and Building Materials, 166, 581-591.

Kumar, P, R., Vijaybaskaran, S., PrasannaVenkatesh, R., Saravannamoorth, S, V. \& Srinath, M. (2015). Effect of steel and polypropylene fibres on the strength characteristics of a cement concrete overlay. International Journal of ChemTech Research, 6(8), 621-627.

Mohammadi, Y., Ghasemzadeh, H. M., Talari, T. B. \& Ghorbani, M. A. (2009). Replacing Fibre reinforced concrete with bitumen asphalt in airports. Proc. World Acad. Sci. Eng. Technol., 58, 30-34.

Paramod, K, K., Desai, A, K., Shivamanth. \& Shrikant, R, B. (2015). Steel fiber reinforced concrete pavement: A review. International Journal for Innovative Research in Science \& Technology, 10(1), 275-276.

Patel, D. \& Patel, V, M. (2015). Application of sugarcane bagasse fibres as concrete composites for rigid pavement. Indian Journal of Research, 4(4), 4-5.

Rai, A., \& Joshi, D. Y. (2014). Applications and properties of fibre reinforced concrete. Int. Journal of Engineering Research and Applications, 4(5), 123-131.

Ramakrishnan, V., Wu, G. Y., \& Hosalli, G. (1989). Flexural fatigue strength, endurance limit, and impact strength of fiber reinforced concretes. Transportation Research Record, (1226).

Salemi, N., \& Behfarnia, K. (2013). Effect of nano-particles on durability of fiberreinforced concrete pavement. Construction and Building Materials, 48, 934-941.

Sheety, M. S. (2013). Concrete technology. published by S. Chand \& Company Ltd., New Delhi-1999.

Sinha, D., Mishra, C, B. \& Solanki, R, V. (2014). Comparison of normal concrete pavement with steel fiber reinforced concrete pavement. Indian Journal of Applied Research, 4(8), 233-235.

Subramani, T. \& Kumaravel, A. (2016). Analysis of polymer fibre reinforced concrete pavements by using ANSYS. International Journal of Application or Innovation in Engineering \& Management (IJAIEM), 132-139.

Suja, A. C. A., \& Marliyas, M. M. (2016). Identification of problems in rigid pavements in Ampara district and proposed solutions. 6th International Symposium 2016 on Multidisciplinary Research for Sustainable Development in the Information Era, pp 222-228. 